\title{
The Improvement of Intellectual Property Consciousness and the Acceleration of the Innovation of High-tech Industry Technology
}

\author{
Qiong Jiang ${ }^{1}$, Lanying $\mathrm{Gao}^{1}$, Lifen Pang ${ }^{1}$ \\ ${ }^{1}$ Law School, Guilin University of Electronic Technology, Guilin, 541004, China
}

Keywords: High-tech industry; Intellectual property rights; Technology innovation; Path

\begin{abstract}
With the development of knowledge economy, economic globalization and high-tech industry, the intellectual property of the high-tech industry enterprises displays the characteristics which are the deepening and the gradual perfection of technology and the increasingly promotion of position in the managerial position of business operation. However, the intellectual property consciousness in our country is generally poor, which fails to facilitate the innovation of high-tech industry technology. Based on this, this text mainly explores the improvement of intellectual property rights and the acceleration of the innovation of high-tech industry.
\end{abstract}

\section{Introduction}

Along with the constant development in the era of knowledge-driven economy, accordingly, the world scientific and technological economy develops rapidly. High-tech industry enterprises play a more and more important role in promoting the development of world economy, becoming the guide of economic development. The distinguishing feature of high-tech industry enterprise development is the soul for the existence of intellectual property and innovation. The intellectual property management which is gradually becoming an important part of the production and operation management of the enterprise plays a more important role. In the process of development, enterprise should emphasize on improving the intellectual property consciousness, establishing a sound intellectual property management system and speeding up the innovation of high-tech industry in order to increase the competitiveness of the enterprise itself.

\section{Formulating the Reasonable Strategy of Enterprise Intellectual Property and Reinforcing the Strategic Management of Enterprise Intellectual Property}

To complete the goal determined by the enterprise, enterprise adopts relevant measures, makes them practicable and finally finishes the mission formulated based on the influence of the internal and external conditions, which is the so-called enterprise strategic management. The strategic management of intellectual property is an indispensable part of the strategic management of high-tech industry enterprise so that enterprise should formulate the reasonable and specified strategic measures and strengthen the intellectual property management according to the concrete practical situation. Based on the requirement of the long-term development of the enterprise, it's very necessary to set up the strategic management of the high-tech industry intellectual property. Only by researching the internal and external factors of the enterprise development, proceeding from the reality and laying down the policy and guidelines related to the development of enterprise intellectual property can the strategic goal of the enterprise intellectual property be realized better and can the strategic decision be more normalized and scientific. The scientific and reasonable formulation of the intellectual property strategy of the high-tech industry enterprise is beneficial for the correct guidance of the establishment and perfection of the management system of the high-tech industry enterprise. Once the management system of the enterprise intellectual property is established, the realization of the development orientation and goal of the enterprise is guaranteed and can obtain the good management effects. The confirmation of the intellectual property strategy of the high-tech industry must be built on the basis of the concrete specific phrase of the enterprise development and the scope of enterprise development. The type of the intellectual property strategy is determined based on the 
practical situation and then it must be guaranteed that the strategy can be made practicable during the process of the high-tech enterprise development. In other words, the intellectual property strategy of the high-tech enterprise development should be determined according to the practical situation due to the different development scale of the enterprise. Generally there are three types: The defensive patent strategy mainly fits the small-sized high-tech enterprise; the mixed patent strategy (the combination of defensive patent strategy and aggressive patent strategy) is mainly suitable for the medium-sized high-tech enterprise; the aggressive patent strategy mainly applies to the large-sized high-tech enterprise. Therefore, the intellectual property strategy of the high-tech industry enterprise must be formulated based on the development scale and orientation of the enterprise and it should be developed into an indispensable part of the overall operation management strategy for the enterprise.

\section{Setting up the Reasonable Administrative Organization of the Enterprise Intellectual Property Duly and Suitably}

The formulation of the intellectual property management strategy of the high-tech enterprise can't be separated from the management organizations of the enterprise intellectual property related to the enterprise. As the department for the specific implementation of the strategy for the enterprise intellectual property management, these organizations must provide a powerful organization guarantee for the implementation of the strategy. But the setting for the management organization of the enterprise intellectual property is not optional and it must be based on the development scale and degree of the enterprise. Setting it according to the actual situation can optimize the resource allocation as well as benefits the reasonable utilization of manpower, financial resources and material resources. According to what we have discussed above, the setting for the intellectual property management strategy of the high-tech enterprise is determined according to the development scale of the enterprise. Firstly, in the small-sized high-tech enterprise, the affairs related to intellectual property are generally undertaken and managed by research and development department or the legal department, which decreases the establishment of special agency. Research and development department or the legal department usually staffs with a few full-time managers of intellectual property to undertake the relevant work. They mainly deal with the daily management transaction of enterprise intellectual property, but enterprise leaders complete the formulation and issue of the enterprise intellectual property strategy under the guidance of enterprise intellectual property strategy and the intermediary agencies in the intellectual property society outside the enterprise. Secondly, medium-sized high-tech enterprise should set up the specialized management organizations of intellectual property and staff with the full-time managers of intellectual property to undertake issues related to the management of intellectual property. Thirdly, large-sized high-tech enterprise needs to build the research center or research institute for the intellectual property policy which formulates the management strategic policy that suits itself best by aiming at the developmental change of the intellectual property policy at home and abroad apart from setting the specialized administrative organizations of intellectual property and full-time managers to undertake the related issues about the intellectual property management. Regardless of the scale of the high-tech enterprise, it should attach importance to the importance of the intellectual property management of the enterprise. Perfecting the intellectual property management organizations is crucial for the increase of enterprise management level. Enterprise should keep improving the management status of the agencies for intellectual property management, research and development department and marketing department to make it accept the management and guidance from the top management of the enterprise. 


\section{Constructing the System for the Enterprise Intellectual Property and Protecting the Enterprise Intellectual Property Effectively}

\section{Establishing and Perfecting the Incentive System of Intellectual Property}

The role of the high-tech enterprise employees in the process of the high-tech enterprise development can't be ignored. The training of technical staff provides eternal source for the development of the enterprise. Improving the enthusiasm, initiative and innovativeness of the high-tech enterprise employees is the important goal for the enhancement of the management level of enterprise intellectual property. Enterprise must set up reasonable intellectual property incentive system supported by the incentive methods and means in various forms in order to realize the goal. Enterprise should encourage the employees to cultivate the enthusiasm and initiative of their own creativity so as to provide condition for the enterprise's application for new intellectual property and boost the core competitiveness of the enterprise in development competition.

The policy-maker of the incentive system for the enterprise intellectual property: intellectual property management organization and human resource management organization set up the concrete requirements, type and the scope about the intellectual property incentive system based on mutual supervision. There must be a definite standard for the incentive methods and grading specification of the intellectual property. In addition, the declaration, appraisal and incentive approach of the intellectual property should be brought to the public and transparent. Only when the true openness and transparency are achieved can the employees be encouraged to develop their positive motivation. Thus the relevant rights and interests of the intellectual property owners are protected and the social credibility is increased. The rewards types of the enterprise intellectual property are various and generally they are formed by the following aspects: innovation awards, technological improvement awards, technological invention awards, patent achievements awards, reasonable suggestion awards, designing scheme awards, research paper awards, achievement transformation awards and achievement award of intellectual property management, etc.

\section{Establishing the Confidential System for the Intellectual Property}

(1) The confidential system for the intellectual property staff. During the process of recruitment and employment, enterprise must conduct the background investigation about the intellectual property of the new employees. Apart from assessing the research and development ability and working ability of the employees, what's more, the enterprise should investigate the employees' performance in the original company and understand their intellectual property background, which helps decrease the situation of the violation of others' intellectual property. According to the laws and regulations related to intellectual property, enterprise must define the service invention and non-service invention of the employees strictly to confirm the attribution of the intellectual property and rights and obligations undertaken by the employees. The phenomenon of stealing intellectual property should be completely eradicated to avoid the unnecessary trouble brought to the enterprise. When the employees especially the enterprise intellectual property employees leave the enterprise, enterprise must sign confidential protocol and non-competition agreement with them based on the relevant stipulation of Labor Contract Law, request them to fill in the departing staff registration form and note the resignation cause and destination. Relevant staff of the enterprise must make it clear to the departing employees that the departing employees have the obligation to keep the business secrets of the enterprise. Enterprise is entitled to ask the departing employees to return the important paper to the enterprise in case of the breach of the enterprise information. (2) The confidential system of the intellectual property data. The enterprise management department and legal department should manage the confidential documents of intellectual property properly by type and level. Generally, there are three levels of the secret paper in the enterprise: top secret, confidential, secret and restricted data. Relevant staff must sort them according to the level of the importance and confidentiality of the documents and adopt different management approaches. In addition, enterprise can build the network database of the intellectual property documents according to the actual situation and set up different 
administration authority based on the sector of the employees in the database. In the database, employees must abide by the stipulations of the enterprise without acting beyond their authority. They can only read the intellectual property documents within their own extent of competence. Different settings for the competence protect the data security at the greatest extent as well as generate the smooth flow of intellectual property documents inside the enterprise, which improves the utilization of the intellectual documents.

\section{Establishing Propaganda Education and Training System for Intellectual property}

To cultivate the intellectual property consciousness of the enterprise employees, train more employees who meet the requirements of the development of high-tech enterprise intellectual property and increase the various qualities of the employees, the formulation for the propaganda education and training system of the enterprise intellectual property is extremely urgent. (1)Enterprise must confirm the clear goal for the realization of the innovation development of intellectual property and try their best to propagandize through various propaganda methods such as using the company's advertising board, launching the knowledge contest of intellectual property, printing and handing out the education brochure of intellectual property, etc. In fact, education and intelligence training for the intellectual property is to improve the intellectual property protection awareness of the staff, promote the stable order of the intellectual property industry and better protect the development of the intellectual property market. To realize the intellectual property education, enterprise managers must possess a comprehensive viewpoint which is that education should benefit everyone including the new and old staff. When the staff first join an enterprise, agency for the enterprise intellectual property management must be sure that the staff understand the culture, development planning and management of the intellectual property. If the result is not ideal, then enterprise must educate them specifically to make them integrate into the big trend of enterprise development, know the development direction of the enterprise in various aspects and strengthen their collaboration consciousness as soon as possible. As to the old staff, enterprise should encourage them to have enough motivation for further study, make them know the condition and procedure for the application of intellectual property and let the owners of intellectual property feel the realization of the fair and just management of enterprise's intellectual property management matters.

\section{Improving Intellectual Property Consciousness and Forming Enterprise Culture}

\section{Strengthening the Intellectual Property Consciousness of the High-tech Enterprise Managers}

Enterprise agency for the intellectual property management improves the enterprise manager's emphasis on intellectual property through carrying out intellectual property training and education so as to make them have profound comprehension and understanding of the intellectual property management and let them realize the crucial importance of high-tech enterprise intellectual property management to the enterprise management and development. If the intellectual property consciousness of the enterprise managers is improved, then they will play the excellent role of exemplary during the process of the enterprise development and also the education of the intellectual property culture for the enterprise staff can get twice the result with half the effort. At the same time, the increase of the enterprise manager's management quality in various aspects can help the enterprise gain optimal configuration of the resources and improve the utilization efficiency of various resources. Therefore, construction for the enterprise intellectual property culture is further promoted.

\section{Strengthening the Intellectual Property Education and Training toward All the Staff in the Enterprise.}

Enterprise conducts various propaganda activities such as carrying out the intellectual property knowledge contest, posting up the leaflets of intellectual property and launching the special lectures for the intellectual property and encourages the broad participation of the staff, which helps form a 
healthy and positive atmosphere for the study of intellectual property knowledge. Also the staff can realize the extreme importance of the enterprise intellectual property to the enterprise development and increase their enthusiasm and initiative for their own study.

\section{Conclusion}

Undoubtedly, along with the development of innovative scientific and technological industry, the merits of the enterprise intellectual property become the measure for evaluating the competiveness of an enterprise. In our country, there appear qualitative changes in the enterprise intellectual property of technological innovation: the enterprise intellectual property of technological innovation grows out of nothing. More and more people realize the importance of intellectual property and the society is surrounded by the rich intellectual property culture. The business system in our country should be completed gradually by taking advantage of the technological innovation of the intellectual property. At present, intellectual property has become the decisive factor for the participation of high-tech enterprise into the market competition. But for the most new-type enterprise of technological innovation, the work of intellectual property still remains on the output phrase of the intellectual property and further development requires the common effort and exploration of all sectors of the society.

\section{Acknowledgments}

This text is the research result of the planned project of Guangxi scientific research and technological development and 'the research of development emphasis and path of the new generation of information industry science and technology. Guicaijiao〔2013〕 No.180

\section{References}

[1] Cai Yajie. The Idea and Strategic Planning of the Intellectual Property Protection in EU. International Research, 2013,(06):243-245.

[2] Sunwei, Jiang Yanfu. Model Building and Empirical Research for the Strategic Selection of the Enterprise Intellectual Property. Science Studies, 2012,(08):1192-1193.

[3] Conglin. A Study of the Market Incentive System of Technological Innovation. Journal of Liaoning Technical University (Social Science Edition) ,2013,(11):130-131.

[4] Zhu Naixiao, Huang Chunhua. A Primary Exploration of the Operation of Enterprise Intellectual Property under Open Innovation. Reform and Stategy, 2011,(02):145-148.

[5] Cheng Enfu, Ding Xiaoqin. The Construction for the Theory and Strategy of Intellectual Property-and the Theory of Comparative Advantages and Competitive Advantages. Contemporary Economic Research. 2003,(09) :123-125.

[6] Dongyu, Sunhe. The Quantitative Analysis of the Influence of Intellectual Property on Industry Innovation-Taking the high-tech Industry as an Example. World Economy Study. 2012,(04) :89-93. 